\title{
O mangá brasileiro: impacto nas mídias e os processos de mestiçagem cultural
}

\section{The Brazilian mangá: impact on the media and the processes of cultural miscegenation}

DOI: $10.46814 /$ lajdv2n5-002

Recebimento dos originais: 10/07/2020

Aceitação para publicação: 30/08/2020

\section{André Noro dos Santos}

Doutor em Comunicação e Semiótica pela Pontifícia Universidade Católica de São Paulo - PUC-SP Instituição: Pontifícia Universidade Católica de São Paulo - PUC-SP

Endereço: Rua Monte Alegre, 984 - Perdizes, São Paulo - SP. CEP 05014-901

E-mail: andrenorosantos57@gmail.com

\section{RESUMO}

Os mangás são histórias em quadrinhos japoneses que fazem parte da cultura pop do Japão, sendo consumidos diariamente por milhares de pessoas. Os japoneses conhecem o mangá desde o século XII, da mistura de diversas expressões artísticas orientais antigas com a cultura ocidental, mas o sucesso só aconteceu quando foi "contaminado" por desenhos e quadrinhos estadudinenses. Com a chegada dos japoneses ao Brasil, o mangá foi introduzido e muito aceito inicialmente entre os descendentes nipônicos, e em seguida por parte dos leitores e artistas brasileiros, que passaram a criar quadrinhos com este estilo. O presente estudo fez parte do meu projeto de doutorado sobre a cultura pop japonesa no Brasil. Os resultados indicam que as áreas de contaminação nos mangás brasileiros são cada vez maiores, com algumas transformações que podem indicar um processo de mestiçagem cultural.

Palavras-chave: cultura pop japonesa, mangá, mangá brasileiro, mestiçagem cultural

\begin{abstract}
Mangás are Japanese comic books that are part of Japan's pop culture, being consumed daily by thousands of people. Japaneses have known manga since the 12th century, from de mixture of various ancient oriental artistic expressions with Western culture, but success only came when it was "contaminated" by American drawings and comics. With the arrival of the Japanese in Brazil, mangá was introduced and widely accepted initially among Japanese descendants, and then by Brazilian readers and artists, who started to create comics with that style. This study was part of my doctoral project on Japanese pop culture in Brazil. The results indicate that the areas of contamination in Brazilian mangá are increasingly larger, with some transformations that may indicate a process of cultural miscegenation.
\end{abstract}

Keywords: Japanese pop culture, mangá, Brazilian mangá, cultural 


\section{INTRODUÇÃO}

O mangá é considerado um dos principais representantes da cultura pop japonesa. Juntamente com os animes, os games e a música ou mesmo o cinema tradicional, os mangás, como são conhecidas as histórias em quadrinhos japonesas, tornaram-se os principais difusores da cultura japonesa no mundo contemporâneo.

O pop japonês começou a ser formado após a II Guerra Mundial, com a ocupação do território nipônico por tropas norte-americanas e a introdução da cultura pop ocidental no Japão. Neste período, o país passou por grandes transformações nas diversas esferas do cotidiano, sejam elas de ordem econômica, política ou cultural. As músicas, os filmes de Hollywood, os comics e as expressões de origem americana tornaram-se parte do cotidiano do povo japonês, ocorrendo uma mudança abrupta de toda uma realidade feudal para um contexto supostamente de pós-modernidade. Hoje, a cultura pop japonesa representa, uma combinação de diferentes conteúdos midiáticos associados a diversos produtos e práticas.

No ocidente, o pop japonês consiste em um conjunto de produtos midiáticos oriundos do Japão relacionados, principalmente, aos mangá (histórias em quadrinhos), anime (desenhos animados), live-action (termo que designa gravação/filmagem de seriados, tanto no cinema quanto na TV), vídeogame, j-music (japanese-music - j-pop, j-rock, anisongs), cosplay ${ }^{1} \mathrm{e}$ modas urbanas (gothic Lolita, decora, yamanba, visual kei).

Porém, de acordo com Luyten (2000), mesmo antes da chegada maciça de produtos culturais vindos de fora, já havia no Japão um mercado de cultura pop que se sustentava com a indústria de mangá e anime.

\section{MANGÁ: A ALMA DA MÍDIA JAPONESA}

Mangá é uma palavra japonesa utilizada para designar histórias em quadrinhos em geral. É formada por dois ideogramas chineses: o man (漫) - que significa "humor ou algo que não é sério", e o gá (画) - que quer dizer “imagem ou desenho". Os japoneses imaginavam mangá como algo divertido e leve (MITSUGO, 2005 apud ROCHA, 2008).

As histórias em quadrinhos no Japão têm origem com os e-makimono que eram desenhos pintados sobre um grande rolo, cujos temas iam aparecendo gradativamente à medida que eram desenrolados. Os e-makimono foram muito populares no século XII, período em que o monge chamado Toba (1053-1140) produziu o mais famoso deles: o chojugiga - desenhos caricatos de animais e pássaros personificando figuras do meio social: monges e nobres, como crítica aos seus

\footnotetext{
${ }^{1}$ Fantasiar-se do personagem de anime preferido.
} 
estilos de vida (MOLINÉ, 2004; NORO, 2014, p. 22). Porém, foi no período Edo ou Tokugawa (1603-1867), com a arte ukiyo-e, que a palavra mangá foi utilizada pela primeira vez, quando Katsushira Hokusai publicou em 1814, o primeiro dos quinze volumes de seu caderno de desenhos, conhecidos como Hokusai Mangá. Ukiyo-e significa "pinturas do mundo flutuante" ou "estampa xilográfica" feitas a partir de pranchas de madeira, geralmente de temática cômica e, algumas vezes erótica, que retratavam assuntos da vida urbana, bem como interpretavam os atores populares do teatro $k a b u k i^{2}$, lutas de $s u m \hat{o}^{3}$, atividades e cenas das áreas boêmias, ou associados à natureza (MOLINÉ, 2004; NORO, 2014, p. 23). (Figura 1)

Figura 1- E-makimono - desenho pintado sobre um grande rolo (A); Chojugiga - desenhos caricatos de animais e pássaros personificando figuras do meio social (B); A arte Ukiyo-e (C).

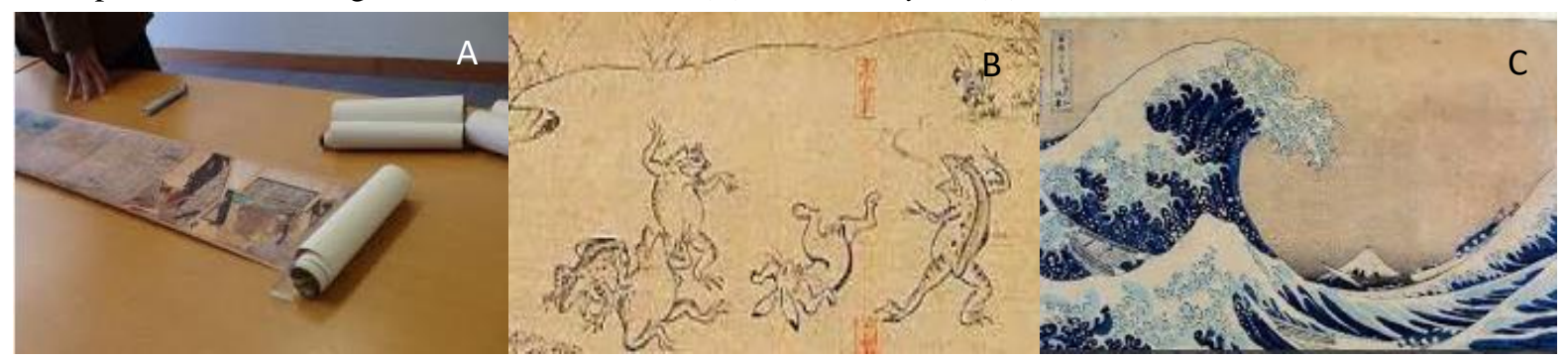

Com a abertura de seus portos e o fim do isolamento durante a Era Meiji (1868-1912), as artes japonesas conquistaram a Europa através das exposições realizadas em Londres (1862) e Paris (1867), resultando em um movimento estético francês de nome Japonaiserie (SCHLOMBS, 2010, p.97-99). A arte Ukiyo-e influenciou Monet, Van Gogh, Tolousse Lautrec (Figura 2), porém os europeus também influenciaram os artistas japoneses (WALTHER, 2007). No momento que a arte é universal ela é passível de apropriações e a história da humanidade está cheia de exemplos.

Figura 2- O retrato de de Père Tanguy, de Van Gogh (1887-88). No plano de fundo várias gravuras ukiyo-ê que o artista colecionava (A); Ponte sob a chuva (1887): Comparativo de arte de Andô Hiroshige (B) e Van Gogh C).

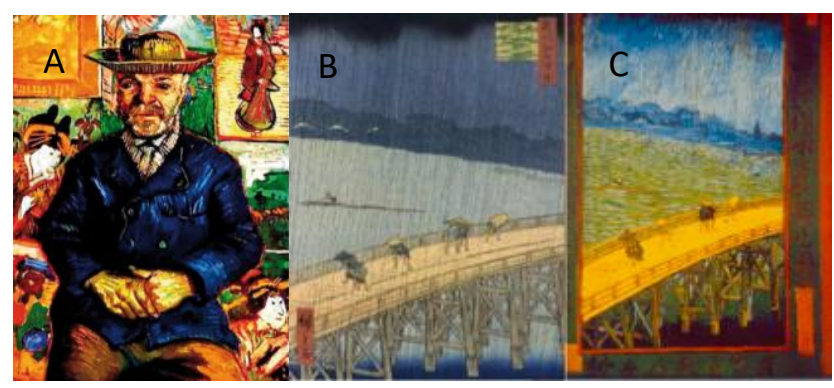

\footnotetext{
${ }^{2}$ Uma forma de teatro japonês conhecida pela estilização do drama e pela elaborada maquiagem usada por seus atores.

${ }^{3}$ Luta de origem japonesa, na qual dois lutadores se enfrentam em um ringue de formato circular.
} 
Por outro lado, com a abertura dos portos, os japoneses também são contaminados por outras culturas, inclusive no que se refere ao desenho humorístico japonês. Em 1862, o inglês Charles Wirgamn publicou a revista The Japan Punch - a primeira revista de humor em estilo ocidental no Japão, inspirada pela revista semanal britânica Punch.

Com o fim da II Guerra Mundial, as mudanças promovidas pela ocupação Americana em 1945 transformariam drasticamente a economia e a cultura do Japão. Antes desse periodo, as histórias em quadrinhos eram em formato de livros, caras e encontradas exclusivamente em bibliotecas ambulantes, porém em um contexto de derrota e a necessidade de encontrar um entretenimento barato e de fácil acesso, ocorreu uma popularização da literatura japonesa com a produção dos Akabon (livros vermelhos), assim chamados devido a cor de sua capa. Eram impressos de baixa qualidade e tinham formato de um cartão postal, com cerca de 20 a 50 páginas. Foi um período em que o povo japonês procurou assimilar o modo de produção americana e, aos poucos, foi se tornando autossuficiente, agregando a influência vinda do exterior a elementos já existentes na sua cultura, desenvolvendo aos poucos um estilo japonês de produzir os quadrinhos japoneses. Naquele período de transformações, Osamu Tezuka adquire grande importância nas produções de mangá. Conhecido como o pai do estilo mangá e inventor da moderna indústria japonesa de mangá, o médico e artista inaugura, em 1950, o estilo de desenho conhecido atualmente: personagens de olhos grandes e expressivos, inspirados nos traços de Walt Disney (MOLINÉ, 2004). Tezuka fez experiências com o formato dos quadrinhos americanos e desenvolveu um estilo ainda mais visual, enfatizando gestos e olhares. As obras de Tezuka influenciaram as produções japonesas da década seguinte, como as histórias em quadrinhos, animações e filmes live-action (filmagem com atores).

O mangá, no Japão, além do entretenimento, alcança um patamar de arte e de retrato cultural de seu povo, com diversas segmentações. Para Luyten (2000), o mangá se integra no ambiente de seu país de origem, seus eventos, festividades e aspectos culturais de sua sociedade, e ambientam suas narrativas em mundos fantásticos e eras míticas, explorando o folclore natal e a história nipônica. Além disso, a grande contribuição cultural do mangá é a sua convergência midiática para outras mídias interligadas e em interação. São as interfaces do mangá com o anime (animação japonesa), com o game, a música (J-pop), RPG (Role-playing game - jogo de interpretação de papeis), que acolheu adaptações de games, e com o advento da internet, o acesso à animação e mangá expandiu-se permitindo o advento do chamado AMV - Anime Music Video - e finalmente o Cosplay, que surgiu nos Estados Unidos na década de 1970, e consiste em vestir-se e brincar de ser o personagem, o ídolo contido na mídia. Hoje é mais conhecido como uma das formas de entretenimento da cultura pop japonesa. 


\section{CARACTERÍSTICAS MARCANTES DO MANGÁ}

No Japão, mangá é o nome dado a qualquer tipo de desenho, sejam eles do próprio país, ou não. Porém, no ocidente, apenas as criações japonesas são denominadas dessa forma. Os japoneses de todas as idades leem os mangás, que por sua vez, representa aproximadamente $40 \%$ de todas as publicações anuais das editoras (FRÉDÉRIC, 2008, p. 755). Existem diversos tipos de narrativas e de traços, que se dividem, basicamente, em cinco estilos: kodomo (para crianças), shoujo (para meninas), shounen (para meninos), seinen (para joves do sexo masculino) e jousei (para jovens do sexo feminino).

Desde a sua primeira obra, o artista Osamu Tezuka definiu o perfil do mangá moderno japonês e o consagrou como produto de mercado do entretenimento. Suas páginas podem ser impressas monocromáticas entre o rosa, verde, roxo, azul ou preto, contendo esporadicamente algumas páginas coloridas, geralmente no início dos capítulos. As cores têm um significado especial para o povo japones, estando associadas a sentimentos. O vermelho com branco é associado à vitalidade e pureza; o verde é vida e espírito eterno; o azul significa o materno, o envolvente, o que sacia; o preto refere-se a mistério, o desconhecido; o amarelo ou dourado, denota prosperidade, numa referência aos campos de arroz amadurecidos (MACHADO, 2009, p. 31).

As revistas contêm entre de 300 a 1000 páginas impressas em papel jornal reciclado de baixa qualidade, parecidas com listas telefônicas tornando-as baratas e acessíveis a qualquer pessoa. A ordem de leitura de um mangá é a inversa da ocidental, ou seja, inicia-se da capa do livro com a brochura à sua direita (correspondendo a contracapa ocidental), sendo a leitura das páginas feita da direita para a esquerda e de orientação vertical e não horizontal.

Uma das principais caracteristicas do mangá é que elas se apresentam em narrativas longas de começo, meio e fim, e sua periodicidade de publicação varia em torno de um ano e meio a dois anos de duração, em publicações semanais, ou seja, as séries costumam ter um final definitivo, ao contrário dos desenhos em quadrinhos do ocidente (BRAGA, 2011, p.71).

O mangá, como principal produto impresso da cultura japonesa, assume um papel integrador do idioma apresentando influências diretas em sua produção, especialmente na representação do som em suas narrativas, as onomatopéias (Figura 3-A). Em muitas produções podem-se conferir caracterizações exageradas de sinais visíveis de sentimentos, como: gotas de água que aparece do lado do rosto do personagem representando constrangimento, dentes e chifres aparecendo repentinamente representando raiva ou maldade, diminuição súbita do personagem dando aspecto de vergonha, nervos estilizados na testa de um personagem, também representando raiva, e tantas outras expresses. As onomatopéias gigantescas e as linhas de movimentos ao fundo da arte, servem também para representar velocidade. Os desenhos trazem a simbologia da representação que indicam os 
eventos ocorridos na cena e a ausência de maiores detalhes deixa ao leitor a capacidade de preenchimento através da imaginação. Há um grande envolvimento emocional. O leitor se coloca no lugar do personagem. Há um dinamismo de cenas, caricaturas, estereótipo e deformação na construção dos personagens e as representações gráficas de sons integram a composição dos desenhos.

Uma das características mais conhecidas do desenho japonês é o tamanho dos olhos, bem definidos, redondos e cheios de brilho e com cores chamativas, como vermelhos, roxos, laranjas, etc. Os corpos, na grande maioria das produções, apresentam-se como detalhes ou silhuetas, com pouca definição e realismo, tal qual lembrando corpos dos fantoches. Como apontado por Braga (2011, p.73), "silhuetas, traços suprimidos e incompletes e desenhos de contorno, tomam lugar dos desenhos finalizados". Os cabelos também adquirem diversos formatos, volumes, penteados e cores diferentes. As meninas normalmente usam laços e afins, e os meninos possuem cabelos espetados, ou compridos, quase sempre com franja. As roupas apresentam design cheio de imaginação e coloridas. Muitos mostram um personagem usando sempre a mesma roupa, pois esse é um modo de caracterizálo. As capas dos mangás são geralmente muito coloridas.

Uma observação importante no mangá é a caracterização do tempo (Figura 3-B). De acordo com Braga, no mangá o tempo é dotado tanto da velocidade como da disfunção do tempo, preocupação de todas as artes orientais (BRAGA, p. 100). O mangá também possui uma linguagem cinematográfica, com perspectivas que valorizam e exploram a ação e o sentimento dos personagens. As linhas de ação e movimento acabam imitando a percepção de captura de camera, sendo usado com frequencia no mangá. Para Susan J. Napier ${ }^{4}$, o estilo mais visual aparece quando a "ação vazava para os quadrinhos adjacentes, impregnando-os e possibilitando aos olhos do leitor mover-se de modo mais dinâmico, mais rápido".

Figura 3 - Exemplo da estética de onomatopeias presentes no mangá (A) e Exemplos de hachuras ${ }^{5}$ e da passagem do tempo quadro a quadro (B)

A

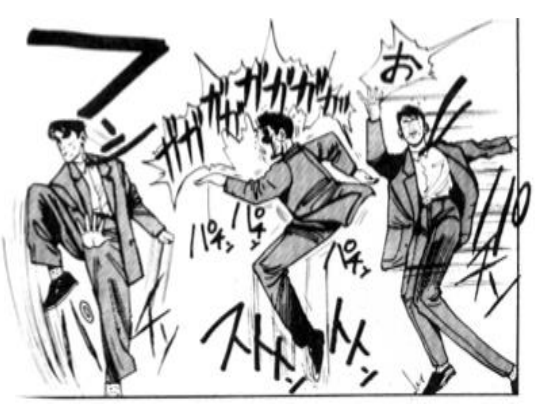

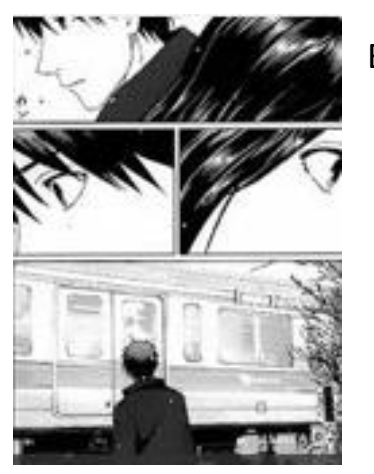

$B$

\footnotetext{
${ }^{4}$ Entrevista de Susan Napier, pesquisadora de mangá e anime nos EUA, para o making of do DVD Animatrix.

${ }^{5}$ Técnica artística utilizada para criar efeitos de tons ou sombras a partir do desenho de linhas paralelas próximas.
} 
Outras características marcantes em relação ao manga, são os pontos de venda inusitados "nas estações de trens ou metrôs, em quiosques com cigarros, chocolates, jornais e refrigerantes, em livrarias ou então em máquinas (como as que vendem cigarros, cerveja, saquê, etc)", que fazem com que sua produção alcance com eficiência essa proliferação do produto no Japão (LUYTEN, 2000 p.44).

\section{HIBRIDAÇÃO E MESTIÇAGEM CULTURAL}

O termo hibridação ou hibridismo tem aplicação em diversos campos do conhecimento humano. Peter Burke (2003), disserta sobre algumas dessas inserções no campo da cultura, música, linguagem e das artes visuais entre outros. Um dos elementos mais importantes no processo de hibridação cultural é aquele relacionado ao surgimento de novas ideias ou espaços culturais resultante da introdução em determinadas culturas de elementos alheios a ela, provocando o diálogo na busca pela construção de novos formatos culturais, e o consequente nascimento de uma "nova ordem cultural", termo utilizado por Peter Burke (2003, p.17).

A idéia de culturas híbridas proposta por Canclini, no início da década de 1990, foi para pensar a modernidade latino-americana, caracterizada pela mistura de culturas. Segundo o autor, os países latino-americanos são resultados da sedimentação, justaposição e entrecruzamento de tradições indígenas, do hispanismo colonial católico e das ações políticas educativas e comunicacionais modernas (CANCLINI, 2003, p.73-74). Na América, predomina uma "heterogeneidade cultural" (ibidem, 2000, p. 212, apud GABRIELLI, 2013, p. 85). Não existe uma preocupação em substituir o tradicional e o antigo, mas torná-lo parte da mesma mescla cultural através da mestiçagem.

Em seu livro, "O pensamento mestiço", o historiador francês, Serge Gruzinski discute a complexidade do tema e aponta várias denominações para o que ele conceitua de mestiçagem.

Misturar, mesclar, amalgamar, (...) etc., são muitas as palavras que se aplicam à mestiçagem e afogam sob uma profusão de vocábulos a imprecisão das descrições e a indefinição do pensamento. A idéia a que remete a palavra 'mistura' não tem apenas o inconveniente de ser vaga. Em princípio, mistura-se o que não está misturado, (...), ou seja, elementos homogêneos, isentos de qualquer 'contaminação' (GRUZINSKI, 2001:42)

Amálio Pinheiro argumenta em seu artigo "Mídia e mestiçagem” que:

Mídia e intelectuais, em sua grande maioria, recusam-se a analisar todo o processo material, cultural e cognitivo da mestiçagem, [...]. O termo aqui não remete à cor, mas a modos de estruturação barrocomestiços que acarretam, pela confluência de materiais em mosaico, bordado e labirinto, outros métodos e modos de organização do pensamento. Tais modos não binários desconhecem o dilema entre identidade e oposição (PINHEIRO, 2006:10) 
$\mathrm{Na}$ mestiçagem encontrada na cultura Contemporânea há a coexistência entre o velho e o novo, as novas tecnologias e as velhas práticas. Constitui-se em um esquema de possibilidades abertas em partes que se combinam e recombinam sem restrições. De acordo com Pinheiro, a mestiçagem é um processo dinâmico sendo constituida como

\begin{abstract}
uma trama relacional, conectiva, cujos componentes não remontam saudosa e solitariamente a instâncias aurorais perdidas, mas sim festejam o gozo sintático dessa tensão relacional que se mantém como ligação móvel em suspensão. Aquilo que pretende permanecer como diferença, fora das texturas fronteiriças em trânsito, corre o risco de transformar-se em homogeneidade carrancuda, repetitiva e totalitária. (ibidem).
\end{abstract}

No Brasil, particularmente, os elementos culturais heterogêneos são os pilares de nosso imaginário cultural e interagem continuamente. Para o sociólogo Bastide (1959, p. 65) "O antigo mistura-se com o novo. As épocas históricas emaranham-se uma nas outras [...]”. De acordo com Campos, "no Brasil, as culturas primitivas se misturam à vida cotidiana ou são reminiscências ainda vivas de um passado recente" (CAMPOS, 1979, p. 193, apud PINHEIRO, 2004).

No que se refere ao mangá, temos um sentido muito mais amplo quando falamos da mestiçagem cultural. Como relatado anteriormente, as histórias em quadrinhos japonesas nasceram a partir de referências da mistura de diversas expressões de arte da cultura oriental antiga com a cultura ocidental.

A cultura japonesa é extremamente sincrética, o que possibilitou com que fossem absorvidos todos os elementos considerados interessantes para o país, amalgamados com características da cultura japonesa e posteriormente transformados em características próprias do Japão, utilizando o lema da Restauração Meiji6: Wakon yosai - espírito oriental, aprendizado ocidental (GREINER, 2008, p. 2). Isso pode ser observado até os dias de hoje, com os eletrônicos japoneses, suas histórias em quadrinhos, animações e muito da sua cultura sendo trazida para o Ocidente como produtos exclusivamente "made in Japan” (SCHULER, 2010).

O pop, de acordo com Greiner (2008, p. 2), “é, pela própria natureza um exemplo de mestiçagem em todos os seus produtos, ideias e fenômenos midiáticos. Mas as suas formulações aconteceram no decorrer de muitas décadas, mesmo no que diz respeito a exemplos específicos como o do mangá”. Os japoneses conhecem o mangá desde o século XII, mas o sucesso só aconteceu quando tal manifestação cultural foi "contaminada" por desenhos, caricaturas, tiras de jornal e quadrinhos ocidentais (GRAVETT, 2006).

A partir dessas técnicas de apropriação, o Japão desenvolveu a identidade da mídia cultural mangá, seu estilo dinâmico, aberto, fluido e de histórias segmentadas, em grandes publicações, com

\footnotetext{
${ }^{6}$ Era Meiji (1868 - 1912) - Periodo em que ocorreu a abertura dos portos japoneses para o ocidente.
} 
histórias que retratam o cotidiano, a cultura e a história japonesa, abertas a novas influências e inovações.

\section{O MANGÁ BRASILEIRO}

O mangá, como discutido anteriormente, embora seja uma manifestação cultural "contaminada" é uma história em quadrinhos utilizado pelos japoneses em seu idioma, como fruto de sua cultura. O Brasil já produz os seus próprios mangás, porém, como considerá-lo mangá "brasileiro", uma vez que a própria palavra não deriva de nosso idioma?

A leitura de mangá chega ao Brasil junto com os imigrantes orientais e seus descendentes, a partir de 1908. Naquela época as revistas eram importadas e distribuídas por distribuidoras especializadas localizadas no Bairro da Liberdade em São Paulo que enviavam para o interior do estado de São Paulo e para o Paraná nas colônias nipônicas.

Somente em 1964, se iniciam as obras do artista Minami Keizi. Foi o primeiro artista de histórias em quadrinhos a alcançar destaque mantendo o estilo cultural japonês em suas produções. Descendente de japoneses nascido no Brasil, desenvolve trabalhos para a Editora Pan Juvenil e para o jornal Diário Popular, onde cria o personagem Tupãzinho, o Guri Atômico, inspirado no personagem Astro Boy de Osamu Tezuka (NAGADO et al., 2011 p.20). Tupãzinho, um índio, desenhado em estilo mangá e com narrativas de origem oriental influenciando a obra nacional, é o primeiro personagem de mangá brasileiro.

A maior publicação de Minami Keizi foi o Álbum Encantado (1966), apresentando contos ilustrados no estilo mangá (NAGADO et al., 2011 p.20-21). A partir daí, vários artistas começaram a desenvolver outros trabalhos no estilo mangá e um deles foi o artista Claudio Seto, que se notabilizou, sendo considerado o maior produtor de mangás brasileiros durante quase duas décadas, com suas histórias de $O$ Samurai. Outros títulos de Seto, publicados pela Editora Edrel nesse período, são Ninja, o Samurai Mágico e O Ídolo Juvenil. Seto é considerado, junto com Minami Keizi, o introdutor do mangá no Brasil, servindo de inspiração para a produção de autores nacionais. Porém, com o encerramento das atividades da editora Edrel na década de 1970, os mangás no Brasil praticamenre sumiram das bancas. Entretanto, no final dos anos de 1980 e começo de 1990, houve a retomada do interesse pelo mangá brasileiro com a publicação do primeiro mangá editado no Brasil, o Lobo Solitário (Kozure Okami), pela editora Cedibra, em 1988. Em seguida foi lançado Akira, que também virou animê, dirigido por Ketsushiro Otomo e publicado pela Editora Globo.

A partir de 1990, com a queda do monopólio da Editora Abril como distribuidora de histórias em quadrinhos vendidas no país e com a crescente aceitação de produtos culturais japoneses, a qualidade das histórias em estilo mangá produzidas antes como experimentação geraram os primeiros 
trabalhos comerciais e com eles, nova maneira de produção de arte nacional, fato que aumentou de maneira progressiva a mestiçagem contida na produção brasileira de histórias em quadrinhos. Essas mudanças impactaram o próprio formato, consume e vendagem de conteúdo publicado no Brasil e a presença dos mangás em todas as bancas e livrarias do país.

Em 2001, a editora Conrad publicou as séries Dragon Ball e Cavaleiros do Zodíaco que já vinham fazendo sucesso na televisão brasileira. Em seguida, foram publicados pela editora JBC, os mangás Samurai X, Sakura Card Captors, Rayearth e Vídeo Girl Ai. Ainda destacam-se: One Piece, Vagabound, Inuyasha, Love Hina, Dark Angel e muitos outros. Seguiram os padrões editoriais brasileiros para revistas em quadrinhos de tamanho menor, tipo formatinho, possivelmente para diminuir os custos dos mangá nacionais. Possuem no máximo 100 páginas, porém, muitos deles seguem o formato original, que exige que a leitura seja feita da direita para a esquerda bem como o folhamento neste sentido, como fazem os japoneses.

De acordo com Borges ${ }^{7}$, “das séries de quadrinhos influenciadas pelo traço dos mangá no Brasil, temos a extrema popularidade de Holy Avenger, criada em 1998 como uma Aventura de RPG”. Logo depois deu origem à uma revista em quadrinhos no estilo mangá muito conhecida em função do sucesso obtido, permitindo ser a publicação de maior longevidade no país. Criada por Marcelo Cassaro e ilustrada por Érica Awano, Holy Avenger atingiu 42 edições publicadas mensalmente ao longo de pouco mais de três anos, tendo gerado também diversas edições especiais relacionadas ao seu universo. Embora seja completamente em estilo mangá, Holy Avenger traz uma temática juvenil focada na realidade do jovem brasileiro, com referências diretas aos seus questionamentos mais comuns, a seus comportamentos e falas, a lugares criados para simbolizar elementos comuns da vida dentro do Brasil e com cada vez mais elementos que a aproximam de uma uniformidade para o idioma, predominando o som abrasileirado até mesmo em suas onomatopeias (Figura 4 A e B).

Outra série de grande popularidade foi a Combo Rangers criada por Fábio Yabu, no final dos anos de 1990 e publicada pelas editoras JBC e Panini. Na série um grupo de heróis armados de amor e coragem luta por um mundo melhor (Figura 4 C).

\footnotetext{
${ }^{7}$ A influência dos mangás nas publicações de quadrinhos no Brasil. Patrícia Maria Borges: Doutora em Comunicação e Semiótica pe la Pontifícia Universidade Católica de São Paulo. http://www.vinetas-sueltas.com.ar/congreso/pdf/Historieta,MangayAnimacion/borges.pdf. Acesso realizado em nov/2014.
} 
Figura 4 - Mangá brasileiro Holy avenger (A); exemplo de onomatopeias em Holy avenger (B) e Capa de Combo Rangers (C)


A adaptação do estilo mangá nas publicações de quadrinhos do Brasil ao que tudo indica, acabou impulsionando o mercado editorial no país e está contribuindo para o crescimento das vendas e para o fortalecimento do mercado de produções independentes. O Brasil criou o seu próprio estilo formatinho $^{8}$ de mangá que perdura por vários anos

Esses novos ares nos mangás nacionais propiciaram aos estudios de Mauricio de Sousa em parceria com a editora Panini, o ambiente propício para a série Turma da Monica Jovem, lançada em 2008 (Figura 5).

A Turma da Monica Jovem apresenta algumas mudanças em relação ao mangá do Japão. A primeira é que eles são de estilos referentes ao mangá oriental, com uma presença grande da cultura $J$-pop, porém sua leitura é feita como nos livros e revistinhas ocidentais, da esquerda para a direita.

Outro fato marcante na mudança feita por Maurício de Sousa na transição da revistinha para o mangá é a diferença física dos personagens. A turma, que antes era representada por meninos e meninas de sete anos, agora vira adolescente e com novos visuais. Essa nova versão traz os personagens adolescentes, com mudanças tanto físicas quanto de características tradicionais dos personagens. Diferente da versão tradicional dos personagens, que ainda continua a ser produzida e vendida normalmente, na nova série em estilo mangá se percebem modificações de estilo e narrativa, para atingir um leitor mais maduro. A grande novidade, é a temática dos assuntos que são abordados, com referência a assuntos sociais, de famílias, bem contemporâneos, condizentes com a realidade, mostrando a força dos jovens e algumas influências perante aos pais. Traz assuntos românticos, intrigas, ciúmes e notícias atuais. Temas antes banalizados, agora são abordados de uma maneira sutil e irreverente.

\footnotetext{
${ }^{8}$ formato de revistas muito usado em histórias em quadrinhos infanto-juvenis no Brasil, como por exemplo pelas revistas da Disney e Turma da Mônica.
} 
Figura 5- Turma da Mônica Jovem número 01 (A); Presença da passagem do tempo (B) e Exemplo de presença de onomatopeias e dos olhos grandes (C)
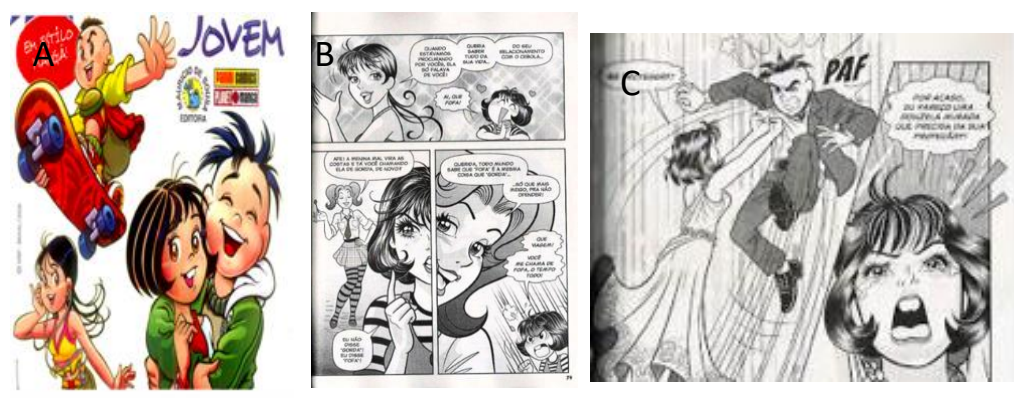

Em 2012, Mauricio publicou Tesouro Verde, com a participação de personagens ilustres do famoso mangakáa Osamu Tezuka, como Astro boy, Safiri e Kimba, unindo-se à Mônica e seus amigos em uma aventura na floresta Amazônica contra uma organização de contrabando de madeira de desflorestamento da Amazônia.

Em relação à linguagem, há diferenças entre os mangás brasileiros e os mangás japoneses. As linguagens de mangás japoneses são um conjunto de técnicas que se utilizam da aproximação entre a grafia e a ilustração, a presença de cenários e elementos de interação, reações exageradas de sentimentos, demonstrados através dos rostos dos personagens e da utilização de onomatopeias gráficas. O mangá brasileiro é focado no sequenciamento da narrativa do que nos sentimentos transmitidos. O que dá ao quadrinho sua marca registrada é o balão, mas o que completa a sua expressão e dá o verdadeiro impacto e grande estética em termos de som são as onomatopéias. No mangá brasileiro, as onomatopéias são menos comuns. Na diagramação apresentam uma quantidade alta de quadros na maioria das páginas e um exagero nos textos presentes nas falas. Porém os dois tipos de mangá se assemelham bastante devido aos olhos grandes, cabelos longos, corpo longo, e outras técnicas modernas do mangá.

\section{CONSIDERAÇÕES FINAIS}

Embora o mangá seja um produto cultural, de extrema simbologia japonesa, a inserção de colônias nipônicas no país deu a seus descendentes uma visão bem diferente, que integra tanto questionamentos originais do Japão como também de nosso Brasil.

Ao propagar e inserir o mangá como produto de mercado brasileiro, artistas como Minami Keizi, Claudio Seta e Julio Shimamoto abriram um novo produto em estilo artístico diferenciado, cujo conteúdo inicial era voltado ao imigrante japonês, mas que, com as mudanças ocorridas durante a abertura comercial japonesa nos anos 80 e a invasão de importações de anime, mangá e demais

\footnotetext{
${ }^{9}$ palavra usada para um quadrinhista no Japão. Fora do Japão mangaká refere-se ao autor do mangá, que normalmente é japonês.
} 
produtos da cultura pop japonesa, se integraram mais à realidade brasileira e permitiram aos poucos, obras e adaptações que evoluíram até quadrinhos totalmente nacionais cujos temas conversam com o público adolescente de nosso país. Logo passaram a carregar os traços culturais brasileiros em suas páginas, em seus diálogos, em suas alusões à realidade conhecida pelo brasileiro, criando, na verdade, histórias em quadrinhos nacionais dentro das técnicas de narração do mangá.

Tudo indica que as obras em quadrinhos em estilo mangá vieram para ficar, com um aumento progressivo de material publicado nos últimos vinte anos tanto os trabalhos traduzidos de importadoras quanto de obras inteiramente nacionais, que aos poucos vão se caracterizando com temáticas de nossa cultura e misturas sutis de técnicas já consagradas modificando a própria cultura das histórias em quadrinhos no Brasil.

Assim, acredita-se que a nova cultura, fruto do encontro entre a cultura brasileira e elementos da cultura japonesa, evidencia novos valores e atitudes singulares no Brasil, próprios da mestiçagem cultural. 


\section{REFERÊNCIAS}

ANDRADE, Tais Janaina Chrisostomo De. Influência da Arte Japonesa do Pós - Impressionismo ao Mangá. Dissertação (Mestrado) - ULBRA, Canoas, RS, 2012, 125 p.

BASTIDE, Roger. Brasil, terra de contrastes. São Paulo: Difel, 1959.

BRAGA, JR, A. X. Desvendando o Mangá Nacional - Reprodução e hibridização nas histórias em quadrinhos. Alagoas: Edufal, 2011

BURKE, Peter. Uma história social do conhecimento: de Gutemberg a Diderot. Rio de Janeiro: Jorge Zahar, 2003. 241 p.

CANCLINI, Néstor Garcia. Culturas Híbridas: Estratégias para entrar e sair da modernidade. 4a Ed. São Paulo: Editora da Universidade de São Paulo, 2003.

DIXON, Andrew Graham. Arte: O guia visual definitivo da arte. São Paulo: Fina Estampa Livros, 2008.

FRÉDÉRIC, Louis. O Japão. São Paulo: Globo, 2008.

GABRIELLI, Lourdes Malerba. Comunicação e publicidade: Mestiçagem e nova oralidade na publicidade en la lengua portuguesa. Revista Lucièrnaga. Facultad de Comunicación Audiovisual. Politécnico Colombiano Jaime Isaza Cadavid. Año 5, Edición 9. Medellín, Colombia. 2013.

GRAVETT, Paul. Mangá - Como o Japão Reinventou os Quadrinhos. São Paulo: Conrad, 2006.

GREINER, Christine. Os corpos j-pop. 2008. Disponível em: http://www.google.com.br/search?client=safari\&rls=en\&q=Os+corpos+do+J-

Pop+++Christine+Greiner\&ie=UTF-8\&oe=UTF-8\&gws_rd=cr\&ei=x1Y8Up3EIZHo9gSW94GABg. Acesso realizado em set. 2013.

GRUZINSKI, Serge. O pensamento Mestiço. Tradução de Rosa Freire dAguiar - São Paulo: Companhia das Letras, 2001.

LUYTEN, Sonia Maria Bibe. Manga: o poder dos quadrinhos japoneses. 2. Ed. São Paulo: Ed. Hedra, 2000.

MACHADO, Carlos Alberto. Processos sócio-educativos dos animencontros: a relação de grupos juvenis com elementos da cultura midiática japonesa. Tese de doutorado - PUC - Rio, 2009.

MOLINÉ, Alfons. O grande livro dos manga. São Paulo. Editora JBC, 2004.

NAGADO, Alexandre, MATSUDA, Michel, GOES, Rodrigo de. Cultura Pop Japonesa - História e curiosidades. (org) março, 2011 JBC, São Paulo, 2011.

NORO, André. A relação homem-máquina na cultura japonsesa: A hibridação entre o corpo tecnológico e humano através da animação Neon Genesis Evangelion. André Noro dos Santos. 1.ed.Curitiba, PR. Ed. CRV, 2014.

PINHEIRO, Amálio. Por entre Mídias e Artes, a Cultura. Rev. GHREBH- número 6, 2004. 
PINHEIRO, Amálio. “Mídia e mestiçagem”. In: Comunicação e Cultura: barroco e mestiçagem. José Amálio Pinheiro (org.). Campo Grande: ed. UNIDERP, 2006.

ROCHA, Marleide de Moura. A arte da animação japonesa. Dissertação (Mestrado em Comunicação e Semiótica). Pontifícia Universidade Católica de São Paulo, 2008.

SCHLOMBS, Adele. Hiroshige. [S.1.]: Taschen, Köln, 2010

SCHÜLER, Vlad. America no Modanisumu: Influencia Ocidental no Japão (1853-1937). Site: Academia.edu.

VERGUEIRO, Waldomiro (org); SANTOS, Roberto Elísio dos (org) O Tico-Tico: centenário da primeira revista de quadrinhos do Brasil. São Paulo: Opera Graphica, 2005.

WALTHER, Ingo F. Paul Gaugin. Taschen, 2007. 